\title{
Renal disease and occupational exposure to organic solvents: a case referent approach
}

\author{
J M HARRINGTON,' HELEN WHITBY,' C N GRAY,' FIONA J REID, ' T C AW,' \\ J A WATERHOUSE ${ }^{2}$ \\ From the Institute of Occupational Health ${ }^{1}$ and Regional Cancer Registry, ${ }^{2}$ University of Birmingham, \\ Edgbaston, Birmingham B15 2TT, UK
}

ABSTRACT Several recent studies have suggested that a relation may exist between exposure to occupational organic solvents and diseases of the kidney-particularly malignancy and glomerulonephritis. Two case referent studies were undertaken in the West Midlands to investigate these possibilities. In the case of renal cancer 54 live cases of biopsy proved adenocarcinoma of the kidney were compared with an equal number of community based healthy referents matched for age, sex, place of residence, and socioeconomic and ethnic grouping. For glomerulonephritis, 50 biopsy proved cases were matched in the same manner with 50 referents. Fourteen other patients were also reviewed who, on biopsy, proved not to have glomerulonephritis. For both sets of cases and their referents each individual was interviewed and a detailed account obtained of medical history and environmental exposures. Exposure to solvents was assessed independently and "blind" in a semiquantitative way by an experienced occupational hygienist. Past exposure was estimated for 10 different solvent types and 17 material types. No relation was found between exposure to solvents and renal cancer or glomerulonephritis. In the case of renal cancer the numbers studied only precluded a fourfold excess risk. For glomerulonephritis, the study, although methodologically superior to most other published studies and of similar size, was of similar power to the renal cancer investigation.

During the past ten years considerable attention has been paid to the health effects of occupational exposure to organic solvents. One aspect of these reports that has generated much interest is the possible link between these solvents and renal disease. The results of such studies have been conflicting, however. Research in this area has tended to concentrate on two types of kidney disease: renal cancer and glomerulonephritis.

In this report we have looked at both diseases using the case referent approach. Renal cancer has tended to be reported by means of cohort studies. By contrast, glomerulonephritis - being an eminently manageable disease these days - has tended to be studied by means of case referent studies. In many cases the cohort studies were hypothesis generating exercises which, by the very nature of the multiple associations reviewed, may well uncover statistically significant excesses. The case referent studies of glomerulonephritis have, almost without exception, had serious methodological flaws. The cooperation of nephrologists and the Regional Cancer Registry has enabled us to study both

Accepted 31 October 1988 these diseases in a way which avoids many of the earlier criticisms, though the statistical power of our investigations was inadequate to exclude other than large risk estimates. The impracticalities and costs of much larger studies, however, rendered them not feasible at present.

Uniquely, we have undertaken a detailed "blind" exposure assessment which we hope will prove a valuable tool in further studies of this nature.

\section{Methods}

The study populations were drawn from the West Midlands and it was decided to use community based referents. For the renal cancer study the study population was drawn from the names of all living patients with histologically proved renal adenocarcinoma (clear cell) diagnosed from May 1984 to April 1985 and recorded in the West Midlands Regional Cancer Registry. By limiting the diagnosis of renal cancer to adenocarcinoma (which forms $80-90 \%$ of all renal cancer), it was hoped that the study would be more specific than extant reports. Limiting the cases to the immediate past 12 months also ensured that most 
cases would be alive. After permission was granted by the hospital doctor concerned, each patient was contacted by post. After agreement to participate by the subject, one of the investigators used a standardised questionnaire to conduct a structured interview at the patient's home.

For the glomerulonephritis study, the cases were identified from those patients attending for renal biopsy at the Queen Elizabeth Hospital, Birmingham, under the care of two consultant nephrologists. The patients were thus collected prospectively and interviewed on the ward before biopsy. To some extent such an interview was blind as some of the patients proved not to have acute glomerulonephritis $(\mathrm{g} / \mathrm{n}$ cases): this group formed a second, smaller, referent population (non- $\mathrm{g} / \mathrm{n}$ cases) as they had experienced the same diagnostic procedures as the cases.

Referent subjects were selected from the community. After each case interview, the general practitioner of the case was contacted and asked to select randomly from within the practice using an agreed procedure, a referent subject of similar age (within five years), sex, and ethnic group as the case. Matching was also made for geographical location and socioeconomic group. Selected controls were then contacted by post and asked to take part in the study. Those who refused to take part were replaced by another person drawn from the same practice and matched in the same way. For ten cases of renal cancer, matching was not possible without resort to using controls from the glomerulonephritis study. For a few glomerulonephritis subjects, the reverse procedure applied. The matching criteria were, however, identical except that geographical location was more approximate-that is, rural, market town, county town, suburb, inner city. In general, the referents were interviewed at home.

The reasons for refusal to participate on the part of referents suggested that convenience motivated the decision. Community based referents, while often more appropriate, are notoriously difficult to recruit compared with hospital referents.

The questionnaire used consisted of three sections. The first part contained questions on personal details and social habits. A full list of past addresses was obtained as well as detailed inquiries about past and present consumption of alcohol, coffee, and cigarettes. The second part reviewed the medical history of the interviewee, including a drug history with specific questions about known nephrotoxins such as gold, penicillamine, and analgesics. The third part of the questionnaire dealt with a life time occupational history and was designed so that the interviewee was allowed to give general information about employment and materials handled, together with details on a number of key groups of materials or processes in which organic solvents were considered important.
Here an attempt was made to reduce the subjectivity of exposure estimation by detailing exposures to specific jobs, materials, and solvents in terms of periods and duration of exposure, as well as how and where the material was handled. This part of the questionnair $\overrightarrow{\text { f }^{2}}$ was detached from the other two and assessed "blind" by an experienced chemist/occupational hygienist an exposure indices (EI) (appendix) were computed fo $\overline{\overline{5}}$ each relevant solvent type up to the time of diagnosis or retirement, whichever was the earlier.

In summary, exposures were categorised as zerow, low, medium, or high and given scores of $0,1,10$, o $\overrightarrow{0}$ 100 respectively. EIs were then calculated by multiply ing the score by the total duration of exposure adjusted so that one year full time heavy exposure corresponded to an exposure index of 100. An EI o 100 could also be attained, therefore, by ten years fuli time moderate exposure etc. An overall EI for "totais solvent" exposures was obtained simply by summing the EIs for individual solvents.

Data from the questionnaire were coded and transe ferred to the university mainframe computer in a format compatible with statistical analysis using thes SPSS-X package. Paired analyses' with odds ratio\& were calculated for two and three exposure categorie $\vec{P}$ according the Schlesselman ${ }^{2}$ and Pike et $a l^{3}$ respeco tively.

\section{Results}

For the renal cancer study, there were 309 coses registered in the West Midlands in 1984-5, of whon 101 were living at the time of the study. Medicas consent was obtained to contact 85 of these and 58 patients agreed to be interviewed. For five of these if was not possible to find matched controls. The stud. population thus consisted of 54 pairs of individuals ( $3 Z^{2}$ men, 22 women). All were white and $95 \%$ describe themselves as Protestant. The mean age ( \pm standar. deviation) was $60.8 \pm 11.5$ years (range 33-85 years for cases and 59.6 \pm 11.8 years (range 32-83 years) fo $\$$ referents. Most cases and controls were classified as socioeconomic group three $(73 \cdot 7 \%$ and $66.0 \%$ respec tively). Most interviewees were retired-reflecting the late age of onset of the tumour.

For the glomerulonephritis study, 67 patients were interviewed in 1985-6, 52 of them had biopsy proves glomerulonephritis, seven had no abnormality, an eight had a different renal pathology. Forty matched referents were also interviewed and 10 suitable referents from the renal cancer study were found for 18 other cases for whom the original matching proceduret had failed. Fourteen subjects whose biopsy diagnosio proved not to be glomerulonephritis were included as a second referent group (non-g/n case). The 50 case्क referent pairs consisted of 37 men and 13 women. Of 
these, 47 were white and three were from the Indian subcontinent, with a mean age of $47.5 \pm 14.8$ years (range 20-79 years) for case and $47.8 \pm 14.8$ (range 22-79 years) for referents. Eighty per cent of the subjects claimed to be Protestant, the remainder being either Roman Catholic, Jewish, Hindu, or Muslim. No case or referent lived near any potentially hazardous individual process or source of environmental pollutant.

Most cases in both studies had previously worked in offices, shops, or in various trades such as metal working, reflecting the industrial bias of the West Midlands.

Forty one (76\%) patients with cancer and $35(65 \%)$ referents smoked cigarettes at some time. Categorisation as light, medium, and heavy smokers was made by the "pack-years" method used by McLaughlin et al. ${ }^{4}$ For women, the percentages did not vary between cases and referents by more than $5 \%$, but for the men the case/referent ratios for light, medium, and heavy were: $40 \cdot 6 / 68 \cdot 0,43 \cdot 3 / 20 \cdot 0$, and $16 \cdot 6 / 12 \cdot 0$ respectively. These differences were not, however, statistically significant. For the glomerulonephritis study, a history of cigarette smoking was common in all subjects, 32 $(64 \%)$ of the $\mathrm{g} / \mathrm{n}$ cases and $37(74 \%)$ of the controls having smoked at some time. Categorisation by light, moderate, and heavy smoking showed no significant differences between cases and referents.

Alcohol consumption, assessed using the criteria of the Health Education Council ${ }^{5}$ and coffee consumption showed no statistically significant differences between cases and referents in either study.

Eight $(14 \cdot 8 \%)$ of the cases of renal cancer compared with one $(2 \%)$ referent has a history of other cancer. The cancers concerned were, however, separate primaries and apparently unconnected with present malignancy (three colon, one rectum, one prostate, one breast, one neurological, one basal cell).

The renal tumours were roughly equally distributed between the left and right kidneys and $29(53.7 \%)$ were stage I, with $46(85.2 \%)$ patients node free and 48 $(88.9 \%)$ metastasis free.

Eighteen $(36 \%)$ of the $\mathrm{g} / \mathrm{n}$ cases and seven $(14 \%)$ of the referents had a history of hypertension, this being the major difference in medical history between the groups. As this condition is a risk factor for renal disease, it seemed prudent to investigate it further. Ten $\mathrm{g} / \mathrm{n}$ cases had suffered from hypertension for several years before developing renal symptoms. All were well controlled at the time of the biopsy. The remaining eight hypertensive $\mathrm{g} / \mathrm{n}$ cases developed raised blood pressure concurrently or after renal symptoms became apparent.

Two $\mathrm{g} / \mathrm{n}$ cases had received gold treatment in the past and three had taken hydrallazine. The patients receiving gold treatment had taken medication 5-15 years previously at normal doses and renal function during treatment was unaffected by the medication. The three patients taking hydrallazine for hypertension had been taking the drug for longer than 12 months at normal therapeutic doses before the onset of renal symptoms. A history of analgesic medication-in particular the non-steroidal antiinflammatory drugs (NSAIDs)-was found in eight $(16 \%) \mathrm{g} / \mathrm{n}$ cases and $11(22 \%)$ referents (a higher frequency than for the renal cancer study, four $(7 \cdot 4 \%)$ and five $(9.3 \%)$ respectively). None of the cases and referents had been taking NSAIDs medication for renal symptoms.

Among the $\mathrm{g} / \mathrm{n}$ cases, $21(42 \%)$ were histologically diagnosed to have focal proliferative glomerulonephritis or IgA nephropathy, eight $(16 \%)$ had mem-

Table 1 Proportion (\%) of subjects claiming exposure to various workplace material types by case and referent groups for glomerulonephritis and renal cancer

\begin{tabular}{|c|c|c|c|c|}
\hline Material type & $\begin{array}{l}\text { Glomerulonephritis } \\
(n=50)\end{array}$ & $\begin{array}{l}\text { Referent } \\
(n=50)\end{array}$ & $\begin{array}{l}\text { Cancer } \\
(n=54)\end{array}$ & $\begin{array}{l}\text { Referent } \\
(n=54)\end{array}$ \\
\hline $\begin{array}{l}\text { Paints, varnishes } \\
\text { Glues } \\
\text { Inks } \\
\text { Dyes } \\
\text { Drycleaning fluids } \\
\text { Degreasing agents } \\
\text { Cleaning materials } \\
\text { Pesticides/herbicides } \\
\text { MacAdam/Asphalt } \\
\text { Fuels, oils, paraffins } \\
\text { Asbestos } \\
\text { Fibreglass/resins/body fillers } \\
\text { Lead, cadmium, mercury, and other heavy metals } \\
\text { Dusty materials } \\
\text { Rubber products } \\
\text { Plastics } \\
\text { Miscellaneous solvents, fumes }\end{array}$ & $\begin{array}{r}30 \cdot 0 \\
16 \cdot 0 \\
4 \cdot 0 \\
2 \cdot 0 \\
0 \\
22 \cdot 0 \\
14 \cdot 0 \\
2 \cdot 0 \\
6 \cdot 0 \\
38 \cdot 0 \\
6 \cdot 0 \\
8 \cdot 0 \\
10 \cdot 0 \\
10 \cdot 0 \\
4 \cdot 0 \\
2 \cdot 0 \\
24 \cdot 0\end{array}$ & $\begin{array}{r}22 \cdot 0 \\
28 \cdot 0 \\
4 \cdot 0 \\
10 \cdot 0 \\
4 \cdot 0 \\
24 \cdot 0 \\
6 \cdot 0 \\
6 \cdot 0 \\
0 \\
32 \cdot 0 \\
2 \cdot 0 \\
2 \cdot 0 \\
8 \cdot 0 \\
0 \\
0 \\
2 \cdot 0 \\
26 \cdot 0\end{array}$ & $\begin{array}{c}25.9 \\
14 \cdot 8 \\
7.4 \\
7 \cdot 4 \\
0 \\
16.7 \\
1.9 \\
1.9 \\
0 \\
37 \cdot 0 \\
11 \cdot 1 \\
7.4 \\
13.0 \\
11 \cdot 1 \\
7.4 \\
5.6 \\
24.1\end{array}$ & $\begin{array}{r}22.2 \\
27.8 \\
5.6 \\
1.9 \\
0 \\
22.2 \\
7.4 \\
3.7 \\
0 \\
29.6 \\
1.9 \\
3.7 \\
11.0 \\
1.9 \\
1.9 \\
3.7 \\
18.5\end{array}$ \\
\hline
\end{tabular}


646

branous nephropathy, and the remainder had either minimal change, acute vasculitic mesangial proliferative, or focal glomerulosclerotic disease. Most patients had had these symptoms for less than four months.

Table 1 shows the proportion of cases and referents reporting exposures to various substance types. The most frequently encountered solvent type materials were fuels and oils, degreasing agents, paints, varnishes, and glues.
Harrington, Whitby, Gray, Reid, Aw, Waterhous $\overline{\bar{e}}$

A large proportion (two thirds to four fifths) o $\overline{\bar{E}}$ cases and controls in both study groups claimed to have had some contact with solvent containing materials, though some of these exposures were judged: to be insignificant by the occupational hygienist and were assigned exposure indices of zero (table 2).

For the purpose of analysis, two classifications of exposure were used. A classification of "exposed" (E $\overline{\text { ? }}$ $>=100)$ and "non-exposed" $(E I<100)$ was establi- $\mathbb{D}$ shed for both the cases with cancer, those witho

Table 2 Proportion (\%) of subjects exposed to different solvent types in case and referent groups at various exposure indices for cancer (54 pairs) and glomerulonephritis ( 50 pairs)

\begin{tabular}{|c|c|c|c|c|c|c|c|c|c|c|c|c|}
\hline \multirow{2}{*}{$\frac{\text { Solvent type }}{\text { Exposure index }}$} & \multicolumn{3}{|c|}{$\begin{array}{l}\text { Cancer cases } \\
(n=54)\end{array}$} & \multicolumn{3}{|c|}{ Referents } & \multicolumn{3}{|c|}{$\begin{array}{l}\text { Glomerulonephritis cases } \\
(n=50)\end{array}$} & \multicolumn{3}{|c|}{ Referents } \\
\hline & $>0$ & $\geqslant 1$ & $\geqslant 100$ & $>0$ & $\geqslant 1$ & $\geqslant 100$ & $>0$ & $\geqslant 1$ & $\geqslant 100$ & $>0$ & $\geqslant 1$ & $\geqslant$ \\
\hline $\begin{array}{l}\text { Unidentified solvents } \\
\text { Aliphatic hydrocarbons } \\
\text { Aromatic hydrocarbons } \\
\text { Alcohols } \\
\text { Ketones } \\
\text { Esters } \\
\text { Ethers } \\
\text { Glycol ethers } \\
\text { Halogenated aliphatics } \\
\text { Halogenated aromatics } \\
\text { Non-solvent chemicals }\end{array}$ & $\begin{array}{l}66 \cdot 7 \\
55 \cdot 6 \\
31 \cdot 5 \\
3 \cdot 7 \\
3 \cdot 7 \\
3 \cdot 7 \\
0 \\
1 \cdot 9 \\
20 \cdot 4 \\
0 \\
81 \cdot 5\end{array}$ & $\begin{array}{l}31 \cdot 5 \\
42 \cdot 6 \\
25 \cdot 9 \\
1 \cdot 8 \\
1 \cdot 8 \\
0 \\
0 \\
1 \cdot 8 \\
4 \cdot 5 \\
0 \\
24 \cdot 1\end{array}$ & $\begin{array}{l}1 \cdot 8 \\
7 \cdot 4 \\
3 \cdot 7 \\
0 \\
0 \\
0 \\
0 \\
0 \\
0 \\
0 \\
0\end{array}$ & $\begin{array}{r}57 \cdot 4 \\
48 \cdot 2 \\
29 \cdot 6 \\
1 \cdot 9 \\
9 \cdot 3 \\
5 \cdot 6 \\
1 \cdot 9 \\
5 \cdot 6 \\
29 \cdot 6 \\
0 \\
66 \cdot 7\end{array}$ & $\begin{array}{l}35 \cdot 2 \\
35 \cdot 2 \\
18 \cdot 5 \\
0 \\
5 \cdot 6 \\
1 \cdot 8 \\
1 \cdot 8 \\
0 \\
20 \cdot 4 \\
0 \\
14 \cdot 8\end{array}$ & $\begin{array}{l}3 \cdot 7 \\
1 \cdot 8 \\
0 \\
0 \\
0 \\
0 \\
0 \\
0 \\
0 \\
0 \\
0\end{array}$ & $\begin{array}{r}56 \\
58 \\
38 \\
4 \\
12 \\
6 \\
0 \\
8 \\
24 \\
2 \\
72\end{array}$ & $\begin{array}{r}26 \\
46 \\
20 \\
4 \\
4 \\
4 \\
0 \\
4 \\
10 \\
0 \\
22\end{array}$ & $\begin{array}{l}2 \\
4 \\
0 \\
0 \\
2 \\
2 \\
0 \\
0 \\
0 \\
0 \\
8\end{array}$ & $\begin{array}{r}56 \\
48 \\
36 \\
0 \\
10 \\
4 \\
0 \\
14 \\
30 \\
0 \\
72\end{array}$ & $\begin{array}{r}28 \\
42 \\
30 \\
0 \\
6 \\
2 \\
0 \\
6 \\
14 \\
0 \\
16\end{array}$ & $\begin{array}{r}6 \\
10 \\
2 \\
0 \\
2 \\
0 \\
0 \\
0 \\
4 \\
0 \\
2\end{array}$ \\
\hline Total solvents & $81 \cdot 5$ & $59 \cdot 3$ & $14 \cdot 8$ & $66 \cdot 7$ & $50 \cdot 0$ & $14 \cdot 8$ & 70 & 50 & 18 & 72 & 60 & 18 \\
\hline
\end{tabular}

Table 3 Contingency tables and odds ratios for two exposure categories for malignant renal disease or glomerulonephritis total solvent exposure

\begin{tabular}{|c|c|c|c|c|c|c|}
\hline & \multicolumn{3}{|c|}{ Renal cancer } & \multicolumn{3}{|c|}{ Glomerulonephritis } \\
\hline & Exposed & Non-exposed & Total & Exposed & Non-exposed & To \\
\hline $\begin{array}{l}\text { Referents: } \\
\text { Exposed } \\
\text { Non-exposed }\end{array}$ & $\begin{array}{l}3 \\
5\end{array}$ & $\begin{array}{r}5 \\
41\end{array}$ & $\begin{array}{r}8 \\
46\end{array}$ & $\begin{array}{l}5 \\
4\end{array}$ & $\begin{array}{r}4 \\
37\end{array}$ & $\begin{array}{r}9 \\
41\end{array}$ \\
\hline $\begin{array}{l}\text { Total } \\
\text { Odds ratio } \\
95 \% \text { confidence interval }\end{array}$ & 8 & $\begin{array}{l}46 \\
1 \cdot 0 \\
0 \cdot 2-4 \cdot 9\end{array}$ & 54 & 9 & $\begin{array}{l}41 \\
1 \cdot 0 \\
0 \cdot 16-6 \cdot 3\end{array}$ & 50 \\
\hline
\end{tabular}

Table 4 Contingency tables and odds ratios for three exposure categories for malignant renal disease or glomerulonephritis and total solvent exposure

\begin{tabular}{|c|c|c|c|c|c|c|c|c|}
\hline & \multicolumn{4}{|c|}{ Renal cancer } & \multicolumn{4}{|c|}{ Glomerulonephritis } \\
\hline & Exposed & Intermediate & Not exposed & Total & Exposed & Intermediate & Not exposed & TotaE \\
\hline $\begin{array}{l}\text { Referents: } \\
\text { Exposed } \\
\text { Intermediate } \\
\text { Non-exposed }\end{array}$ & $\begin{array}{l}3 \\
3 \\
2\end{array}$ & $\begin{array}{r}3 \\
8 \\
13\end{array}$ & $\begin{array}{r}2 \\
8 \\
12\end{array}$ & $\begin{array}{r}8 \\
19 \\
27\end{array}$ & $\begin{array}{l}5 \\
3 \\
1\end{array}$ & $\begin{array}{l}2 \\
9 \\
5\end{array}$ & $\begin{array}{r}2 \\
9 \\
14\end{array}$ & $\begin{array}{rr}9 & \text { N } \\
21 & N \\
20 & \omega\end{array}$ \\
\hline $\begin{array}{l}\text { Total } \\
\text { Odds ratio }(95 \% \text { confidence } \\
\text { Exposed/non-exposed } \\
\text { Intermediate/non-exposed }\end{array}$ & $\begin{array}{l}8 \\
\text { d interval): }\end{array}$ & 24 & $\begin{array}{ll}22 & \\
1 \cdot 30 & (0 \cdot 31 \\
1.54 & (0.69\end{array}$ & $\begin{array}{c}54 \\
-8 \cdot 50) \\
-4 \cdot 10)\end{array}$ & 9 & $\begin{array}{ll}16 & \\
0.67 & (0.03- \\
0.50 & (0 \cdot 12\end{array}$ & $\begin{array}{c}25 \\
-3 \cdot 36) \\
-1 \cdot 36)\end{array}$ & 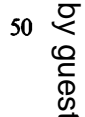 \\
\hline
\end{tabular}


glomerulonephritis, and their respective referents. The resulting contingency tables are shown in table 3 . A three category grouping of "non-exposed" $(\mathrm{EI}<1)$, intermediate $(1 \leqslant \mathrm{EI}<100)$, and exposed $(\mathrm{EI} \geqslant 100)$ is outlined in table 4. The odds ratio for solvent exposed versus non-exposed in table 3 was $1 \cdot 0$ for both renal cancer and glomerulonephritis. The odds ratio for exposed versus non-exposed and intermediate exposure versus non-exposure in table 4 was 1.3 and 1.54 respectively for renal cancer. For glomerulonephritis it was 0.67 and 0.5 respectively. The $95 \%$ confidence intervals for all the odds ratios calculated straddled 1.0 , indicating no statistically significant increased odds of solvent exposure in cases of renal cancer and glomerulonephritis compared with their referents. Neither set of contingency tables show a statistically significantly raised odds ratio, neither is there any evidence of any trend with increasing exposure trends.

\section{Discussion}

The renal cancer study failed to show any statistical significant differences between cases and referents for any of the variables dealing with social habits, drug medication, or medical history. Although there was a significant difference between cancer cases and their referents with regard to past history of malignant disease, there was no histologically plausible explanation for a link when the tumour sites were reviewed. The lack of any association with cigarette smoking contrasts with the findings of McLaughlin et al. ${ }^{6}$ They showed a "causal" relation with an estimated attribution of renal cancer to smoking of $30 \%$ for men and $24 \%$ for women. The differing results here could be due to the lower power of the present study to detect such a relation. If there is indeed a causal relation between renal cancer and cigarette consumption the absence of evidence here weakens any other conclusions that may be drawn from a study of only 54 pairs.

The higher number of transport workers in the group with cancer was the only result of note from an assessment of occupation. The numbers, though small, might support the findings of Rushton and Alderson (unpublished data). The drivers in Rushton and Alderson's study are, however, not entirely comparable with the group described in the present study. Furthermore, unpublished correspondence between Alderson and the Institute of Petroleum after the nonrefinery worker drivers report suggests that there is some doubt about the validity of the originally reported excess (P Jones, personal communication).

For the glomerulonephritis study, there was also no statistically significant difference noted between cases and referents for any of the variables dealing with social habits, drug medication, or medical history of hypertension. In addition, the use of nephrotoxins such as gold or hydrallazine was only evident in the glomerulonephritis group, though there was little reason to believe that these small numbers produced a serious confounding effect in this study.

The classification of diagnoses indicated that $40 \%$ of the cases had a diagnosis of proliferative glomerulonephritis. This figure, together with those of the other diagnostic categories noted from the renal biopsy results compares well with the percentages cited by Van de Laan ${ }^{7}$ and Ravnskov et al. ${ }^{8}$ In the study by Bell et al all the patients had proliferative glomerulonephritis. ${ }^{9}$

There were no major differences in frequencies of job types between the groups, though for the solvent type used, exposure to dyes was more prevalent in the referent group than in the $\mathrm{g} / \mathrm{n}$ cases. Those with cancer showed a tenfold excess of asbestos and dust exposure whereas glues show a twofold deficit. Exposure assessments for asbestos, however, were judged to be insignificant. More importantly, an independent assessment of lifetime solvent exposures showed no significant excess for either cases with cancer or with glomerulonephritis whether consideration was given to "total" solvent exposure or specific solvent type. Latency could be important here for renal cancer but as most of the cases and referents were retired, this was not deemed a major source of bias. The glomerulonephritic cases and referents were younger but latency is less likely to be as relevant here.

Nevertheless, a wide range of chemicals, including some aromatic hydrocarbons, $\mathrm{N}$-nitroso compounds, and metal salts have been shown to induce renal cancer in experimental animals. A dose dependent association between unleaded petrol vapour and renal cancer has been shown for male rats ${ }^{10}$ though it has been suggested that the male rat kidney is uniquely prone to renal disease. In well defined epidemiological studies, however, such associations in man have not been confirmed. Most studies investigating renal cancer and petroleum based chemicals have been of the cohort design and most have been generated from cohorts of petroleum industry employees. In 1984 a review of cancer risks in oil refinery workers critically examined eight industry based and six general population surveys." The reviewers concluded that methodological shortcomings may be responsible for some of the contradiction in the published results, and thought that, overall, refinery populations did not seem to experience any "substantial rises" in cancer risks. What remained unrevealed was whether smaller sections of the workforce experienced an excess of certain cancers-particularly melanoma, brain, stomach, kidney, and pancreas.

In the same year Enterline and Viren specifically 
addressed the epidemiological evidence for an association between petrol and kidney cancer. ${ }^{12}$ They concluded that there was little support for an aetiological link in the 12 cohort, three case referent, and three ecological studies included in their review. Similar conclusions had been reached in a workshop on the subject a year earlier. ${ }^{1314} \mathrm{~A}$ more recent review of 15 cohort studies confirmed the lack of a clear relation between organic solvents and renal cancer. Risk ratios ranged from 0.44 to 1.55 , but none was statistically significant. ${ }^{15}$ None of these cohort studies showed any dose response effect nor any difference in renal cancer rates by duration of employment. Two studies with "non-positive" findings had considerable statistical power and thus lend credence to the argument against a causal association. ${ }^{716}$

A methodological shortcoming of all of the above studies was the lack of quantitative estimations of hydrocarbon or petroleum product exposure. Furthermore, diagnostic specificity was absent and cigarette smoking habits unknown. Some of the shortcomings of earlier work were largely overcome in the recent case referent study of risk factors and renal carcinoma undertaken by McLaughlin and his coworkers. ${ }^{6}$ Their study of 495 cases and matched controls reviewed occupational factors as well as lifestyle and medical history. Patients with renal cancer had a significantly increased exposure to petroleum, tar, and pitch products (relative risk 1.6). An update of this study, however, showed a relative risk of 1.0 for exposure to petroleum. ${ }^{4}$ No quantitative assessment of exposure was made.

The present cancer study, though much smaller than the McLaughlin series, attempted to collect detailed occupational exposure histories from cases and referents and to assess exposure to specific organic solvents using a structured, computerised methodology developed for this study. We are not aware of any similar case referent study.

Whereas reports of occupational links between renal cancer and organic solvents have come mainly from cohort studies of petroleum populations, the putative association of solvents with glomerulonephritis has come from animal studies, case reports, and a few case referent studies. Reviews of these studies have been recently made by Churchill $e t ~ a l,{ }^{17}$ Phillips, ${ }^{18}$ and Harrington. ${ }^{15}$ Case reports have dealt with a variety of non-malignant kidney conditions such as Goodpasture's syndrome, ${ }^{19}$ membranous nephropathy, ${ }^{20}$ and subacute proliferative glomerulonephritis. ${ }^{21}$ Descriptions of potential causative agents include hydrocarbon solvents, paints, and jet fuel. Although rather vague, the product types implicated are more specific than in the study on renal cancer. It is generally agreed, however, that case reports do little more than point the way to the need for more analytical epidemiological studies.

Out of six case referent studies undertaken to investigate glomerulonephritis and exposure t hydrocarbon solvents, five gave a positive, but weak correlation. ${ }^{22-25}$ The sixth study by Van de Laan' aime $\bar{\Phi}$ to replicate that of a previous weakly positive study of Ravnskov et $a l^{8}$ but the results were "non-positive. The designs of all but two of these studies, howeve have been criticised on methodological grounds. Un fortunately, these studies of Van de Laan an Ravnskov et al exhibit conflicting results which d8 nothing to resolve the aetiological question. In brieș the methodological shortcomings of most of the

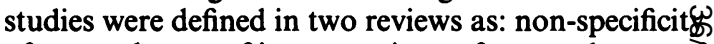
of cases, the use of inappropriate referents, the use of unblinded interviewers, the problem of recall bias, an 9 the failure to quantify the hydrocarbon solvent exposure. ${ }^{718}$ In a recent study which attempted to overcome some of these criticisms 50 patients witb biopsy proved glomerulonephritis were questionedo "blind" for solvent exposure using the method des? cribed by Ravnskov." The referents were hospital based. The results indicated an occupational exposur 6 to solvents significantly greater for case subjects tha $\frac{}{2}$ for controls.

The present study investigated a similar sized groug but used community based referents and a structured, computerised assessment of past exposure to solvents Comparing the present results with the three beate extant studies shows a concordance with one ${ }^{7}$ and ${ }^{2}$ disagreement with the other two. ${ }^{89}$ It is, howe impossible to compare the assessment of solven exposure between the studies as methods vary com siderably. None of the previously published studieg attempted any systematic quantitative assessment of solvent exposure. We believe that the methods used i⿱ this study improve on the previous assessment of solvent exposure in terms of reliability and re producibility as well as specificity and, in addition. reduce somewhat the subjective element in the retrop spective respondent based histories of exposure. The question of latency in the renal cancer study was nof addressed and could be a source of bias. Most of the interviewees were retired however, thus this facto may not be a major one. Furthermore, the choice of referent group in the present study is considered to be 9 superior option to hospital based referents, ${ }^{26}$ despito the fact that such community based referents are fai more difficult to recruit. The need to obtain a detailed work history necessitated the use of live cases. There is, however, no reason to believe that the dead "cases స్ differ in any significant way from the referents so far a.ّ exposures are concerned.

Nevertheless, a major difficulty of interpretation emanates from the relatively weak statistical power of both the renal cancer study and the glomerulone? 
phritis study, even though the size of the glomerulonephritis section is as large as any published. A case referent study based on 50 pairs has a $90 \%$ power to detect a relative risk of four or greater if the prevalence of exposure to solvents in the general population is $50 \%{ }^{2}$ Whatever their size, case referent studies are prone to bias. ${ }^{26}{ }^{27}$ In this study refusal to participate was largely the result of the poor state of health of some of the patients. We have acquired no evidence to suggest that these refusals could be construed as relevant to the broad health outcomes nor to the exposure assessments. Recall bias could have been relevant but evidence from drug histories-which could be confirmed to a large extent from hospital records-suggests that this was not so.

The exposure questionnaire has been modified in the light of this study but nevertheless represents a considerable advance over previous attempts to quantify past exposures to solvents. In general, it parallels the assessment procedure of Gerin et al ${ }^{28}$ but includes a more detailed analysis of the exposures elicited.

In short, the study design was methodologically relevant, provided a detailed and moderately objective assessment of exposure, and yet failed to show any relation between exposure to organic solvents and renal cancer or glomerulonephritis. The power of the study, however, precludes a definitive judgment on causation as much larger studies would be required to be reasonably certain of detecting a twofold excess risk.

\section{Appendix}

\section{EXPOSURE ASSESSMENT AND CALCULATION OF EXPOSURE INDICES}

Retrospective exposure assessment involved the use of a detailed interviewer administered questionnaire on occupational history and non-occupational activities which could involve relevant exposures. The complexity and branching nature of the questionnaire made it unsuitable for self administration. Completed questionnaires were identified by numbers which hid the medical status of the subject and were given to the occupational hygienist for assessment. All objective data on the questionnaire-for instance, dates, frequency and duration of exposures, material codes, etc - were coded and recorded on a database without further interpretation. Exposures were categorised from the job and material descriptions by reference to an independent checklist of exposures to solvents. The results of exposure categorisation were recorded on the database. Final calculation of exposure indices (EIs) was performed by a computer program that used a system of scoring for exposure categories in which low exposures earned one point, medium 10, and heavy 100 points. EIs were obtained by multiplying the exposure score by the total duration of exposure measured in standard work years. Thus one year's light exposure, as might be experienced by a forecourt attendant in a self service petrol station, would earn an EI of one, whereas one year's heavy exposure-for example, during certain types of shoe assembly work-would earn an EI of 100.

We are grateful to Dr Adu and Dr Michael for access to their renal patients as well as to the many general practitioners who afforded access to patients and agreed to our requests for referents. We are also indebted to Professor Copas of the department of statistics at the university for his advice on analyses.

The study was supported by a research grant from the Institute of Petroleum.

\section{References}

1 Fleiss J. The analysis of data for matched samples. In: Statistical methods for rates and proportions. New York: John Wiley, 1973: $72-80$.

2 Schlesselman JJ. Case control studies: design, conduct and analysis. Oxford: Oxford University Press, 1982.

3 Pike MC, Casagrande J, Smith PE. Statistical analysis and individually matched case control studies in epidemiology: factor under study a discrete variable taking multiple values. $B r$ J Prev Soc Med 1975;29:196-201.

4 McLaughlin JK, Blot WJ, Mehl FS, Stewart PA, Venable FS, Fraumeni JF. Petroleum related employment and renal cell cancer. J Occup Med 1985;27:672-4.

5 Health Education Council. In: That's the limit - a guide to sensible drinking. London: Health Education Council, 1985.

6 McLaughlin JK, Mandel JS, Blot WJ, Schumann LM, Mehl ES Fraumeni JF. A population based case-control study of renal cell carcinoma. J Natl Cancer Inst 1984;72:275-84.

7 Van De Laan G. Chronic glomerulonephritis and organic solvents. Int Arch Occup Environ Health 1980;47:1-8.

8 Ravnskov U, Forsberg B, Skerfving S. Glomerulonephritis and exposure to organic solvents. Acta Med Scand 1979;205:575-9.

9 Bell GM, Gordon ACH, Lee P, et al. Proliferative glomerulonephritis and exposure to organic solvents. Nephron 1985;40: 161-5.

10 MacFarland HN, Ulrich CE, Holdsworth CE. A chronic inhalation study with unleaded gasoline vapour. Journal of the American College of Toxicology 1984;3:231-48.

11 Savitz DA, Moure R. Cancer risks among oil refinery workers. J Occup Med 1984;26:662-70.

12 Enterline PE, Viren J. Epidemiologic evidence for an association between gasoline and kidney cancer. Environ Health Perspect 1985;62:303-12.

13 Higginson J, Muir CS, Buffler PA. The epidemiology of renal carcinoma in humans with a note of the effects of gasoline. In Proceedings of a workshop on kidney effects of hydrocarbons. Washington: American Petroleum Institute, 1983:322-51.

14 Raabe GK. Kidney cancer epidemiology in petroleum related studies. In: Proceedings of a workshop on kidney effects of hydrocarbons. Washington: American Petroleum Institute, 1983:393-408.

15 Harrington JM. The health experience of workers in the petroleum manufacturing and distribution industry-a review of the literature. Am J Ind Med 1987;12:475-97.

16 Divine BJ, Barron V. Texaco mortality study. I. Mortality among refinery, petrochemical and research workers. $J$ Occup Med 1985;27:445-7. 
17 Churchill DN, Fine A, Gault MH. Association between hydrocarbon exposure and glomerulonephritis-an appraisal of the evidence. Nephron 1983;33:169-72.

18 Phillips SC. A review of the human kidney effects of hydrocarbon exposure. In: Advances in environmental toxicology. Vol III. Renal effects of petroleum hydrocarbons. Princeton: Princeton Scientific Publishers Inc, 1985:270-321.

19 Beirne GJ, Brennan JT. Glomerulonephritis associated with hydrocarbon solvents. Arch Environ Health 1972;25:365-9.

20 Ehrlenreich T, Yunis SL, Chung J. Membranous nephropathy following exposure to volatile hydrocarbons. Environ Res 1977;14:35-45.

21 Von Scheele C, Althoff P, Kempni V, Schelin H. Nephrotic syndrome due to subacute glomerulonephritis-association with hydrocarbons. Acta Med Scand 1976;200:427-9.

22 Zimmerman SW, Groehler K, Beirne GJ. Hydrocarbon exposure and chronic glomerulonephritis. Lancet 1975;iii:199-201.
23 Lagrue G, Kamalodine T, Guerroro J, Hirbec J, Zhepova $\overline{\mathbf{R}^{2}}$ Bernandin JF. Nephropathies glomerulaire primitives et inhala tion de substances toxique. Journal of Urology and Nephrologs 1977;4-5:323-9.

24 Ravnskov U. Exposure to organic solvents-a missing link im post-streptococcal glomerulonephritis. Acta Med Scand 1978 203:351-6.

25 Finn R, Fennerty RG, Ahmad R. Hydrocarbon exposure an glomerulonephritis. Clin Nephrol 1980;14:173-95.

26 Cole P. The evolving case-control study. J Chronic Dis 1979;3 15-27.

27 Ibrahim MA, Spitzer WO. The case-control study: the problem and the prospect. J Chronic Dis 1979;32:139-44.

28 Gerin M, Siemiatycki J, Kemper H, Begin ID. Obtaining occupational exposure histories in epidemiological case-control studies. J Occup Med 1985;27:420-6.

\section{Correspondence and editorials}

The British Journal of Industrial Medicine welcomes correspondence relating to any of the material appearing in the journal. Results from preliminary or small scale studies may also be published in the correspondence column if this seems appropriate. Letters should be not more than 500 words in length and contain a minimum of references. Tables and figures should be kept to an absolute minimum. Letters are accepted on the understanding that they may be subject to editorial revision and shortening.

The journal now also publishes editorials which are normally specially commissioned. The Editor welcomes suggestions regarding suitable topics; those wishing to submit an editorial, however, should do so only after discussions with the Editor. 